\title{
BLOOD PRESSURE AND PULSE RATE LEVELS
}

FIRST PAPER: THE LEVELS UNDER BASAL AND DAYTIME CONDITIONS*

T. ADDIS

SAN FRANCISCO

This study is primarily concerned with the question of normal blood pressures and pulse rates under varying conditions. The observations on patients cover only a restricted field and are introduced, in the main, as illustrations of the deductions which may be drawn from comparison with the normal data. The work falls naturally into two parts, one, the measurement of the level of pressure and pulse rate under fixed conditions, with which this paper is concerned; the other, the measurement and interpretation of the changes in pressure and pulse rate induced by alteration of the conditions, which are dealt with in a succeeding paper. Most of the observations were made on soldiers at Camp Lewis, Wash. For the opportunity to do this work I am indebted to Dr. Kerr, who was in charge of the medical division of the Base Hospital, to Dr. Northington and Dr. Fulton who were successively in command, and to Lieutenant-Colonel Gibner who was camp surgeon.

The level of pressure and pulse rate under what we have called "basal" and "daytime" conditions is the subject of this paper. In work on metabolism the word basal is used to indicate that the measurements have been made in the early morning before food has been taken and before the subject has done any muscular work. In this paper it has the same significance. The observations were made in the early morning before the subjects had risen from bed. In most cases they were first awakened by the application of the arm band. By daytime observations are meant those taken at various times during the day after the subjects had risen from bed and had taken food. In all cases the readings were made while the men were lying down. Those who had recently done any strenuous muscular work were excluded. Most of the work was done on Sundays when bad weather had kept the men relatively inactive in their barracks.

The incentive to collect data on the normal basal blood pressure and pulse rate was derived from a difficulty in diagnosis in a group of patients who presented signs and symptoms resembling those seen in hyperthyroidism. While recruits from the first and second drafts were arriving at Camp Lewis, men were seen every day who combined an enlargement of the thyroid gland with tachycardia, tremor and evident

\footnotetext{
* From the Medical Department of Stanford University Medical School.
} 
signs of nervous instability. It was recognized from the first that only a small percentage were likely to have exophthalmic goiter for true exophthalmos was rare. The hyperthyroidism which arises in some cases of endemic goiter is uncommon at the age period of the men we were examining, and we were dealing with a condition which was not at all uncommon. It was noted also that similar signs and symptoms were found in men who had no thyroid enlargement, and on this account a statistical study was made of the incidence of tachycardia, tremor and various other abnormalities in large groups of men with and without increase in the size of the thyroid gland. ${ }^{1}$ This survey showed that there was no definite relationship between the thyroid enlargement and the occurrence of tachycardia, tremor and other evidences of vascular and nervous instability. It appeared, then, that the thyroid enlargement was only a chance concomitant which was frequently present simply because endemic goiter was so extremely prevalent in many of the districts from which the recruits were drawn, ${ }^{2}$ It thus seemed still more unlikely that hyperthyroidism could be a frequent cause of the condition. We felt confident that the great majority of these men were suffering from the condition described under the names irritable heart, neurocirculatory asthenia and effort syndrome. But in individual cases there was often uncertainty, and this led to a search for some objective clinical evidence of an increase in basal metabolism, to take the place of the direct measurements of oxygen consumption which we could not at that time obtain.

A relationship has been shown to exist between the pulse rate and the metabolism when they are measured under the same conditions, and for some time we placed a great deal of weight on the pulse rate counted in the early morning before the patients had risen from bed. When the pulse rate was less than 70 in patients who during the day had tachycardia and tremor, we felt that we could probably exclude hyperthyroidism. However, the relation between pulse rate and rate of metabolism is not always close. It seems likely that the reason for the relation which does exist is to be found in a more general relation between the metabolic activity of the body as a whole and the activity of the circulatory system of which the pulse rate is only a partial expression. The true measure of circulatory activity is the volume flow of blood per unit of time. It has been shown by combined circulatory and metabolic measurements that there is a close correspondence between volume flow of blood and rate of metabolism. The volume flow of blood per unit of time has been determined in man by

1. Addis and Kerr: Arch. Int. Med. 23:316 (March) 1919.

2. Kerr: Arch. Int. Med. 24:347 (Sept.) 1919. 
Lindhard ${ }^{3}$ and by Means and Newburgh. ${ }^{4}$ The output of the heart was measured by gas analysis methods over a short space of time during which the pulse rate was counted. The average output at each beat of the heart was thus calculated, and the volume flow of blood per minute obtained from the product of the systolic output per beat and the pulse rate per minute. In subjects on whom measurements were made before and after exercise a remarkably close agreement was found between the increase in this product and the increase in the rate of metabolism produced by exercise. Bainbridge ${ }^{5}$ recently pointed out that a comparison of such experiments shows that the two factors in the product which measures the volume flow of blood-the systolic output per beat and the pulse rate-may each vary, although for given metabolic conditions the product will remain constant. The required volume flow of blood may at one time be obtained mainly by increase in systolic output and at another time mainly by increasing the pulse rate. This circumstance seems to account for the absence of any very direct relation between pulse rate and rate of metabolism, and it also indicates that if we were able to get some clinical measure of the systolic output at each beat of the heart, even though it were only approximate, we might have. a better index of the rate of metabolism than can be obtained from the pulse rate alone.

Measurements of systolic output by the nitrous oxid or any other blood analysis method are usually out of the question in clinical work. But von Recklinghausen ${ }^{6}$ has shown that the pulse pressure varies directly with the systolic output per beat, except for such variations as may arise from differences in the coefficient of elasticity in the arteries. This has recently been experimentally confirmed by Bazett. ${ }^{7}$ It appeared, therefore, that the product of the pulse pressure and the pulse rate might have a close relation to the rate of metabolism unless differences in the elasticity of the arteries in different individuals were so marked as seriously to distort the relation between systolic output and pulse pressure. Even if that should be the case the P. P. (pulse pressure) $\times$ P. R. (pulse rate) product might still be a useful clinical method for the purpose of obtaining an indication of the direction of metabolic changes in the same individual at different times.

These considerations, but especially the results of experiments on the effect of exercise on the P.P. $\times$ P.R. product which are given in the next paper, made it seem worth while to collect data on

3. Lindhard: Arch. f. d. ges. Physiol. 161:233, 1915.

4. Means and Newburgh: J. Pharmacol. \& Exper. Therap. 7:441. 1915.

5. Bainbridge: Physiology of Muscular Exercise. 1919.

6. Von Recklinghausen: Arch. f. exper. Path. 56:1. 1907.

7. Bazett: Proc. Roy. Soc. London. Ser. B 90:415. 1917. 
the P. P. $\times$ P. R. product in normal persons under basal conditions in order to get a control for similar observations on patients. The results, of course, do not allow of any conclusion as to whether the P. P. $\times$ P. R. product has a closer or even as close a relation to the basal metabolic rate as the pulse rate alone. That question can only by answered by direct comparison with a parallel series of determinations of basal metabolism. But the figures have an interest of their own apart from any possible significance they may have in connection with basal metabolism. In addition to these early morning observations, the pressure and pulse rate was measured on another group of normal individuals during the day under the conditions we have defined above for daytime observations.

In both the basal and daytime observations the pressure and pulse rate were observed simultaneously, the pulse rate being counted by an assistant while the systolic and diastolic pressures were being read. A mercury sphygmomanometer with a broad arm band was used. The diastolic pressure was taken at the end of the third phase or at the cessation of sound in those subjects in whom no fourth phase could be distinguished.

In Table 1 the basal and daytime results on normals are compared. The basal averages were obtained from eighty-nine observations on seventy-six persons, and the daytime figures from 300 measurements on 300 persons. Both groups comprised soldiers on active service between the ages of 21 and 31 .

These results are a contribution toward the accumulation of data required for a definition of what is meant by normal pressure and pulse rate. Though a great deal of work has been done on the subject, the figures have usually been presented in such a way as to preclude the application of the statistical methods which are essential for an adequate understanding of their significance. The variability of the systolic, diastolic and pulse pressure has been admirably dealt with by Kilgore, ${ }^{8}$ and Alvarez and his associates ${ }^{9}$ have published a complete statistical review of a large series of measurements of systolic pressure in normal individuals. Alvarez arranged his data in groups according to the ages of the subjects, but no significant change in the systolic pressure was found between the ages of 21 and 31 . We may, therefore, compare his average systolic pressure of 126.5 on 2,930 men with our average of 127.4 on 300 men, and his coefficient of variation of 12 per cent. with ours of 13 per cent. So far as the diastolic and pulse pressure are concerned, the only data available for the determination

8. Kilgore: Lancet 2:236, 1918.

9. Alvarez, Wulzen, Taylor and Starkweather: Arch. Int. Med. 26:381 (Sept.) 1920. 
of variability seem to be the frequency distributions of Barach and Marks ${ }^{10}$ and of Kilgore. ${ }^{8}$ All these results were obtained under conditions similar to those we observed in our daytime observations. Only a few isolated measurements were found which were carried out under what we have called basal conditions.

Table 1.-Normal Data. Basal Measurements of Seventy-Six Normals Compared with Daytime Measurements on Three Hundred Normals

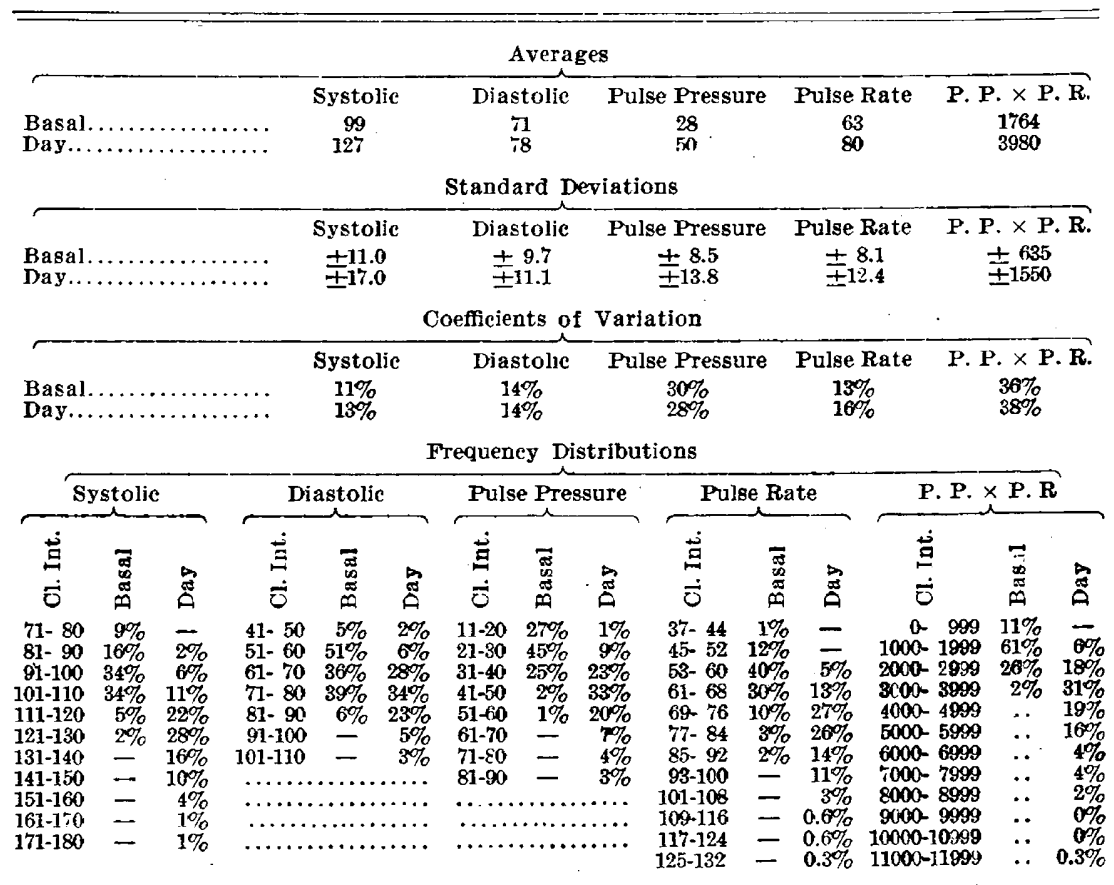

The differences between the basal and day averages show how markedly the level of pressure and pulse rate is influenced by factors associated with daytime activities. A measure which would be "normal" for the day would be unusually high if it were found under basal conditions in the early morning, so that the interpretation of the significance of any given pressure or pulse rate depends, in the first place, on a knowledge of the conditions under which the observation was made.

During the day the P. P. $\times$ P. R. product increases more markedly. than the other measurements because both pulse pressure and pulse rate rise. The increase in pulse pressure occurs in spite of a slight

10. Barach and Marks: .Arch. Int. Med. 13:648 (June) 1914. 
increase in diastolic pressure and is due entirely to the rise in systolic pressure. Since the systolic pressure, other things being equal, is determined by the amount of blood pumped out by the heart, we may assume that during the day the output of the heart at each systole is increased. The increase in pulse rate shows that there are a larger number of systoles per unit of time. The changes induced by daytime conditions are, therefore, such as we should expect to find if there were an increase in the volume flow of blood.

There are two factors which are certainly of importance in raising the daytime levels. One of them is the effect of food, which has been shown by Weysse and Lutz ${ }^{11}$ to result in an increase in systolic pressure and pulse rate. The other factor is exercise. In Table 2 averages are given from a group of ten normal persons under basal and daytime conditions and after a shorter or longer period of exercise.

TABle 2.-Effect of Exercise on Blood Pressure and Pulse Rate levels of Normal Individuals

\begin{tabular}{|c|c|c|c|c|c|}
\hline Conditions & Systolic & Diastolic & Pulse Pressure & Pulse Rate & P. P. $\times$ P. R. \\
\hline $\begin{array}{l}\text { Basal.................. } \\
\text { Day time............. } \\
\text { Short exercise........ } \\
\text { Longer exercise....... }\end{array}$ & $\begin{array}{r}100 \\
121 \\
137 \\
168\end{array}$ & $\begin{array}{l}65 \\
77 \\
59 \\
42\end{array}$ & $\begin{array}{r}35 \\
44 \\
78 \\
126\end{array}$ & $\begin{array}{r}60 \\
74 \\
81 \\
114\end{array}$ & $\begin{array}{r}2100 \\
3256 \\
6320 \\
14360\end{array}$ \\
\hline
\end{tabular}

There is another factor-excitement-which may have been equally operative under both basal and daytime conditions. In Table 3 daytime averages from a group of twenty-seven men who were not excited are compared with averages from a group of twenty-seven men who admitted that the examination excited them because they were afraid that something would be found which would prevent them going over with their regiment.

TABle 3.-Effect of Excitement on the Daytime Levels of Pressure and Pulse Rate in Normal. Individuals

\begin{tabular}{cccccc}
\hline Conditions & Systolic & Diastolic & Pulse Pressure & Pulse Rate & P. P. $\times$ P. R. \\
No excitement........... & 129 & 79 & 43 & 80 & 340 \\
Excitement............ & 154 & 89 & 65 & 92 & 5980 \\
\hline
\end{tabular}

These three factors, food, exercise and excitement, all have their most marked effect on the systolic pressure and pulse rate. The measurement which is least influenced is the diastolic pressure. Food has little or no effect; exercise lowers it, and excitement increases it, but it remains the most stable measure, so that in daytime observations on patients when all three factors are operative, an increase in diastolic

11. Weysse and Lutz: Am. J. Physiol. 37:330: 1915. 
pressure is likely to be of more significance than the same degree of increase in systolic pressure.

The significance of any measurement which deviates from the normal average depends on the variability or degree of dispersion of the normal measurements. This variability is given in the standard deviation. The relation between the actual deviation of the measurement and the standard deviation can be expressed in a concrete way as odds against the possibility that any normal subject would give as high or a higher level of pressure or pulse rate than the measurement in question. A discussion of this statistical method will be found in a recent very complete study of blood pressure and pulse rate in children by Faber and James. ${ }^{12}$ In Tables 4 and 5 the odds for a series of measurements for basal and daytime conditions are given.

Table 4.-Basal Condrtions. The Odds That a Normal Individual Under Basal Conditions Will Show as High or a Higher Level of Pressure and Pulse Rate as Those Given Below

\begin{tabular}{|c|c|c|c|c|c|c|c|c|c|c|c|}
\hline $\begin{array}{l}\text { Sys. } \\
\text { tolic }\end{array}$ & Odds & $\begin{array}{l}\text { Dias- } \\
\text { tolie }\end{array}$ & Odds & $\begin{array}{c}\text { Pulse } \\
\text { Pressure }\end{array}$ & Odds & $\begin{array}{l}\text { Pulse } \\
\text { Rate }\end{array}$ & Odds & \multicolumn{2}{|c|}{ P. P. $\times$ P. R. } & \multicolumn{2}{|c|}{ Odds } \\
\hline 118 & 1 in 24 & 88 & 1 in $2 \bar{\jmath}$ & 43 & 1 in 26 & 77 & 1 in 24 & 2900 & & in & \\
\hline $\begin{array}{l}118 \\
119\end{array}$ & $\begin{array}{ll}1 \text { in } & 24 \\
1 \text { in } 29\end{array}$ & $\begin{array}{l}88 \\
89\end{array}$ & 1 in 32 & $\begin{array}{l}40 \\
44\end{array}$ & 1 in 33 & 78 & 1 in 31 & 2950 & & in & 33 \\
\hline 120 & 1 in 36 & 90 & 1 in 40 & 45 & 1 in 44 & 79 & 1 in 42 & 3000 & & in & 39 \\
\hline 121 & 1 in 44 & 91 & 1 in & 46 & 1 in & 80 & 1 in & 3050 & 1 & in & us \\
\hline 122 & 1 in 55 & 92 & 1. in 67 & 47 & 1 in 80 & 81 & 1 in 76 & 3100 & & in & 58 \\
\hline 123 & 1 in 69 & 98 & 1 in 86 & 48 & 1 in 106 & 82 & 1 in 106 & 3150 & & in & 69 \\
\hline 124 & 1 in 86 & 94 & 1 in 112 & $\begin{array}{l}40 \\
49\end{array}$ & 1 in 147 & 83 & 1 in 147 & 3200 & 1 & in & 09 \\
\hline 125 & 1 in 104 & 95 & 1 in 147 & 50 & 1 in 208 & 84 & 1 in 208 & 3250 & 1 & in & 104 \\
\hline 126 & 1 in 141 & 96 & 1 in 204 & 51 & 1 in 306 & 85 & 1 in 303 & 3300 & & in 1 & 128 \\
\hline 127 & 1 in 182 & 97 & 1 in 270 & 52 & 1 in 417 & 86 & 1 in 435 & 3350 & 1 & in 1 & 161 \\
\hline $\mathrm{T} 28$ & 1 in 233 & 98 & 1 in 385 & 53 & 1 ín 625 & 87 & 1 in 666 & 3400 & 1 & in 2 & 20 \\
\hline 129 & 1 in 313 & 99 & 1 in 526 & 54 & 1 in 910 & 88 & 1 in 1000 & 3450 & 1 & in 2 & 25 \\
\hline 130 & 1 in 417 & 100 & 1 in 770 & 55 & 1 in 1430 & $\ldots$ & ........... & 3500 & & in 3 & \\
\hline 131 & 1 in 555 & 101 & 1 in 1000 & ... & ......... & & & 3550 & & in 4 & \\
\hline 132 & 1 in 741 & $\ldots \ldots$ & ......... & $\cdots$ & a....... & $\because$ & 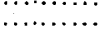 & 3600 & 1 & in & \\
\hline 133 & 1 in 1000 & $\ldots$ & ........... & $\ldots \ldots$ & ......... & $\ldots$ & $\cdots$ & 3650 & & in & \\
\hline & & & & & & & & $\begin{array}{l}3700 \\
3750\end{array}$ & 1 & & \\
\hline
\end{tabular}

The odds given in these tables refer only to the normal, they cannot be interpreted as odds in favor of abnormality. To know the latter, we should have to measure the standard deviation of the group of abnormals to which the patient happened to belong. However, for practical purposes of classification of cases it is permissible arbitrarily to decide that any patient whose pressure exceeds a certain level shall be regarded as "abnormal." The choice of that level will depend on the nature of the work. It is sometimes desirable to have a standard so narrow that all cases with a possible pathologic tendency to hypertension will be detected. Then a level at which the odds are that only one normal out of, say, twenty-five would give as high a pressure may be taken. But at other times one may desire to separate a group of

12. Faber and James: Am. J. Dis. Child. 22:7 (July) 1921. 
cases in which it is practically certain that there are no normals. Then a level at which the chances are that only one out of 1,000 normals will be so high may be selected as the dividing point.

These statistical methods give no information as to the nature of the factor responsible for any unusually high pressure which may be found in a patient. If it is a daytime observation it may be the result of an abnormal susceptibility to purely external and evanescent causes such as food, excitement or exercise, rather than the inner and more lasting perversion of function we are accustomed to think of in connection with hypertension.

Table 5.-Daytime Conditions. The Odds That a Normal Individual

Under Daytime Conditions Will Show as High or a Higher Level of Pressure or Pulse Rate as Those Given Below

\begin{tabular}{|c|c|c|c|c|c|c|c|c|c|c|}
\hline $\begin{array}{l}\text { Sys- } \\
\text { tolic }\end{array}$ & \multicolumn{2}{|c|}{ Odds } & $\begin{array}{l}\text { Dias- } \\
\text { tolic }\end{array}$ & Odds & $\begin{array}{c}\text { Pulse } \\
\text { Pressure }\end{array}$ & e Odds & $\begin{array}{l}\text { Pulse } \\
\text { Rate }\end{array}$ & Odds & \multicolumn{2}{|c|}{ P. P. $\times$ P. R. Odds } \\
\hline 160 & 1 in & 23 & 97 & 1 in 23 & 74 & 1 in & 102 & 1 in & 6799 & 1 in \\
\hline 101 & 1 in & 26 & 98 & 1 in 29 & 75 & 1 in 29 & 103 & 1 in 32 & 6800 & 1 in \\
\hline 162 & 1 in & 29 & 99 & 1 in & 76 & 1 in & 104 & 1 in & 6900 & 1 in \\
\hline 163 & 1 in & 33 & 100 & 1 in & $\pi$ & 1 in & 105 & 1 in & 7000 & 1 in \\
\hline 164 & 1 in & 38 & 101 & 1 in 52 & 78 & 1 in & 106 & 1 in 55 & 7100 & $1 \mathrm{in}$ \\
\hline 165 & 1 in & 44 & 102 & 1 in & 79 & 1 in & $10 \%$ & 1 in & 7200 & 1 in \\
\hline 166 & 1 in & 51 & 103 & 1 in & $\mathbf{8 0}$ & 1 in & 108 & 1 in & 7300 & 1 in \\
\hline 167 & $1 \mathrm{in}$ & 58 & 104 & 1 in 104 & 81 & 1 in & 109 & 1 in 101 & 7400 & 1 in \\
\hline 168 & 1 in & 69 & 105 & 1 in 133 & 82 & 1 in & 110 & 1 in 128 & 7500 & 1 in \\
\hline 169 & 1 in & 78 & 106 & 1 in 170 & 83 & 1 in 119 & 111 & 1 in 161 & 7600 & 1 in 104 \\
\hline 170 & 1 in & 91 & 107 & 1 in 222 & 84 & 1 in 145 & 112 & 1 in 204 & 7700 & 1 jn 122 \\
\hline 171 & 1 in & 106 & 108 & 1 in 286 & 85 & 1 in 182 & 113 & 1 in 250 & 7800 & 1 in 147 \\
\hline 172 & 1 in & 125 & 109 & 1 in 385 & 86 & 1 in 222 & 114 & 1 in 323 & 7900 & 1 in 175 \\
\hline 173 & 1 in & 147 & 110 & 1 in 500 & 87 & 1 in 270 & 115 & 1 in 416 & 8000 & 1 in 208 \\
\hline 174 & 1 in & 175 & 111 & 1 in 666 & 88 & 1 in 333 & 116 & 1 in 526 & 8100 & 1 in 256 \\
\hline 175 & $1 \mathrm{jn}$ & 207 & 112 & 1 in 910 & 89 & 1 in 417 & 117 & 1 in 714 & 8200 & 1 in 303 \\
\hline 176 & 1 in & 250 & 113 & 1 in 1250 & 90 & 1 in 526 & 118 & 1 in 910 & 8300 & $I$ in 385 \\
\hline 177 & 1 in & 294 & ... & .......... & 91 & 1 in 666 & 119 & 1 in 1250 & 8400 & 1 in 455 \\
\hline 178 & 1 in & 345 & $\ldots \ldots$ & .......... & 92 & 1 in 834 & $\ldots$ & ......... & 8500 & 1 in 588 \\
\hline 179 & 1 in & 417 & $\ldots \ldots$ & $\ldots \ldots \ldots \ldots$ & 93 & 1 in 1111 & $\ldots$ & $\ldots$ & 8600 & I in 714 \\
\hline 180 & 1 in & 500 & & $\ldots \ldots \ldots$, & & & & & $8 \% 00$ & 1 in 833 \\
\hline 181 & 1 in & 625 & $\ldots$ & ........ & $\ldots$ & $\ldots$ & & & 8800 & 1 in 1111 \\
\hline 182 & 1 in & 740 & & & & & & & & \\
\hline 183 & 1 in & 909 & & & & & & & & - \\
\hline 184 & 1 in 1 & 1111 & & & & & & & & \\
\hline
\end{tabular}

The striking difference between the averages of normal individuals under basal and daytime conditions are the clearest illustration of the necessity for uniformity in the conditions under which the observations are made. It is not possible to use the basal normal for the evaluation of pressures obtained in patients in the morning if they have been out of bed even for a moment. The normal values for daytime'measurements cannot be taken as a standard for observations made on patients who are standing or sitting, or on those who have just walked up a flight of stars. The variability of normal blood pressure under such conditions is not known.

\section{IRRITABLE HEART}

The measurements on patients were carried out under the same basal conditions as were observed with the normal controls. The cases 
were in each instance tentatively diagnosed as cases of irritable heart with the exception that a reservation was made in regard to the possibility of true hyperthyroidism. These cases were selected from a larger group on the following basis. The patients all complained of one or more of three cardiac symptoms-dyspnea, palpitation, precordial pain; one or more of the three symptoms of vascular instability-dizziness, flushing, fainting, and, in addition, they gave some evidence of general nervous instability. In the great majority of cases these symptoms antedated enlistment, and often dated back to childhood. Persons presenting these symptoms following some infectious disease were excluded, and in none could a diagnosis of organic cardiac disease be made. In almost all cases, tachycardia and tremor were present at one time or another. The hands were usually cyanosed, cold and clammy. These patients thus seemed to belong to what has been called the constitutional type of irritable heart, or neurocirculatory asthenia. Basal pressure and pulse rate measurements were made on 138 of these patients. In Table 6 the averages, standard deviations and frequency distributions are given.

Table 6. - Basal Measurements on Patients Provisionally Diagnosed as "Irritable Heart" Cases

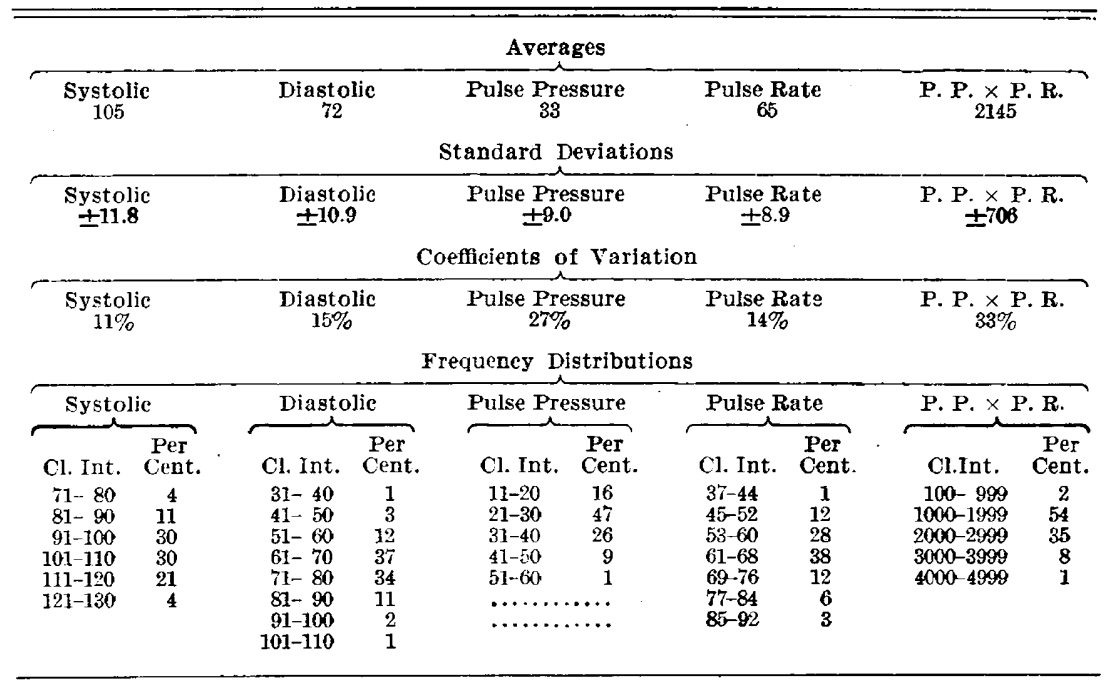

The average level of all the measurements on the patients is slightly higher than the basal averages for normals given in Table 1 . The greatest increase is in the P. P. $\times$ P. R. product. In this case the difference is statistically significant, for when the "probable difference between the averages" is determined the odds are found to be about 64 
to 1 against the possibility that the increase from 1,764 for the normals to 2,145 for the patients can have arisen simply as the result of chance. It would appear, then, that some factor not operative in the normal cases had increased the P. P. $\times$ P. R. This might have been the inclusion of some cases of hyperthyroidism or the same difference might be due to a greater nervous excitability in the patients. But whatever the cause may have been, it is evidently of relatively slight importance, since all but 1 per cent. of the observations on patients fall within the range of variation of the normal. It seemed to us to be of particular significance that patients whose condition during daytime examinations showed so many points of resemblance to hyperthryroidism should in the early morning, under basal conditions, give evidence of an inactivity and quietude of the circulatory system which seemed inconsistent with the hypothesis of a state of continuing metabolic activity, such as exists in hyperthyroidism. It is true that in individual cases we were sometimes still in doubt, but the important question at the time was one of group diagnosis; and the fact that a normal basal product, as well as a normal basal pulse rate, was found in practically all these patients was of aid, in conjunction with other evidence, in leading us to reject a diagnosis of hyperthyroidism for this group of patients. At a later date Peabody, Wearns and Tompkins ${ }^{13}$ showed the correctness of this conclusion by demonstrating that patients of this type, many of whom had been diagnosed as having hyperthyroidism, had an entirely normal rate of basal metabolism.

An increase in the P. P. $\times$ P. R. product may be found in patients in whom there is no reason to suspect any increase in the rate of metabolism. This is shown in the daytime measurements given in Table 7 .

TABLE 7.-Daytime Measurements Showing Increase in P.P $\times$ P.R. Product

\begin{tabular}{cccccc}
\hline Conditions & Systolic & Diastolic & Pulse Pressure & Pulse Rate & P. P. $\times$ P. R. \\
Normals............... & 127 & 78 & 50 & 80 & 3920 \\
Patients............. & 190 & 113 & 77 & 79 & 6083 \\
\hline
\end{tabular}

The patients were nineteen middle aged or old people who had hypertension. They were unselected cases, except that those with cardiac decompensation or advanced renal disease were excluded. There were no indications whatsoever of any increased metabolic activity, rather the reverse. Yet their P. P. $\times$ P. R. product is markedly increased, but it is an increase due to a rise in only one factor of the product, the pulse pressure. Furthermore, it has been shown that any decrease in the elasticity of the large vessels between the heart

13. Peabody, Wearn and Tompkins: Med. Clin. N. America 2:507, 1918. 
- and the brachial artery will result in an increase in pulse pressure because the pressure will rise higher at each systole, if the vessels are rigid than if they give way to some extent when the blood is forced into them by the heart. ${ }^{6}$ Hence, when a product is found to be high only because of an increase in pulse pressure it would be well to suspect the presence of an inelastic aorta, rather than an increased output of the heart.

Daytime measurements were also made on 156 patients who were believed to have an irritable heart. This group includes the 138 persons whose basal pressures and pulse rates were obtained. The averages given in Table 8 are derived from 580 observations.

Table 8.-Daytime Measurements on Patients Provisionally Diagnosed as "Irritable Heart" Cases

\begin{tabular}{|c|c|c|c|c|c|c|c|c|c|}
\hline \multicolumn{10}{|c|}{ Averages } \\
\hline \multicolumn{2}{|c|}{$\begin{array}{l}\text { Systolic } \\
131\end{array}$} & \multicolumn{2}{|c|}{$\begin{array}{c}\text { Diastolic } \\
75\end{array}$} & \multicolumn{2}{|c|}{$\begin{array}{l}\text { Pulse Pressure } \\
55\end{array}$} & \multicolumn{2}{|c|}{$\begin{array}{l}\text { Pulse Rate } \\
\quad 85\end{array}$} & \multicolumn{2}{|c|}{ P. P. $\underset{4680}{\times \text { P. R. }}$} \\
\hline \multicolumn{10}{|c|}{ Standard Deviatious } \\
\hline \multicolumn{2}{|c|}{$\begin{array}{l}\text { Systolic } \\
\pm 18.5\end{array}$} & \multicolumn{2}{|c|}{$\begin{array}{l}\text { Diastolic } \\
\pm 11.5\end{array}$} & \multicolumn{2}{|c|}{$\begin{array}{l}\text { Pulse Pressure } \\
\pm 17.5\end{array}$} & \multicolumn{2}{|c|}{$\begin{array}{l}\text { Pulse Rate } \\
\pm 13.4\end{array}$} & \multicolumn{2}{|c|}{ P. P. $\times \underset{ \pm 1862}{ }$} \\
\hline \multicolumn{10}{|c|}{ Coefficients of Variation } \\
\hline \multicolumn{2}{|c|}{$\begin{array}{c}\text { Systolic } \\
14 \%\end{array}$} & \multicolumn{2}{|c|}{$\begin{array}{c}\text { Diastolic } \\
15 \%\end{array}$} & \multicolumn{2}{|c|}{$\begin{array}{c}\text { Pulse Pressure } \\
\text { 32\% }\end{array}$} & \multicolumn{2}{|c|}{$\begin{array}{l}\text { Pulse Rate } \\
16 \%\end{array}$} & \multicolumn{2}{|c|}{ P. P. $\underset{43 \%}{\times \text { P. R. }}$} \\
\hline \multicolumn{10}{|c|}{ Frequency Distributions } \\
\hline \multicolumn{2}{|c|}{ Systolie } & \multicolumn{2}{|c|}{ Diastolie } & \multicolumn{2}{|c|}{ Pulse Pressure } & \multicolumn{2}{|c|}{ Pulse Rate } & \multicolumn{2}{|c|}{ P. P. $\times$ P.R. } \\
\hline Cl. Int. & $\stackrel{\text { Per }}{\text { Cent. }}$ & Cl. Int. & $\begin{array}{l}\text { Per } \\
\text { Cent. }\end{array}$ & Cl. Int. & $\stackrel{\text { Per }}{\text { Cent. }}$ & Cl. Int. & $\stackrel{\text { Per }}{\text { Cent. }}$ & Cl.Int. & $\begin{array}{c}\text { Per } \\
\text { Cent. }\end{array}$ \\
\hline $71-80$ & 0.2 & $31-40$ & 1 & $11-20$ & 1 & $37-44$ & .. & $0-999$ & \\
\hline $81-90$ & 0.5 & $41-50$ & 2 & $21-30$ & 7 & $45-52$ & $\because$ & $1000-1999$ & 2 \\
\hline $91-100$ & 5 & $51-60$ & 10 & $31-40$ & 17 & $53-60$ & 2 & $2000-2999$ & $\mathbf{1 3}$ \\
\hline $101-110$ & 8 & $61-70$ & 26 & $41-50$ & 27 & $61-68$ & 8 & $3000-3999$ & 23 \\
\hline $111-120$ & 21 & $71-80$ & 36 & $51-60$ & 20 & $64-76$ & 22 & $4000-4999$ & 28 \\
\hline $121-130$ & 27 & $81-90$ & 21 & $61-70$ & 15 & $77-84$ & 23 & $5000-5999$ & 15 \\
\hline $131-140$ & 18 & $91-100$ & 4 & $71-80$ & 6 & $85-92$ & 20 & $6000-6999$ & 10 \\
\hline $141-150$ & 10 & $101-110$ & 1 & $81-90$ & 4 & $93-100$ & 14 & $7000-7999$ & 6 \\
\hline $151-160$ & 6 & $111-120$ & 0.2 & $91-100$ & 2 & $101-108$ & 7 & $8000-8999$ & 3 \\
\hline 161-170 & 3 & ........... & $\ldots .$. & $101-110$ & 1 & $100-116$ & 5 & $9000-9999$ & - $\frac{8}{2}$ \\
\hline $17-180$ & 2 & .......... & $\cdots$ & $111-120$ & 0.2 & $117-124$ & 1 & $10000-10099$ & 1 \\
\hline $181-190$ & 0.4 & .............. & $\cdots$ & $121-130$ & 0.2 & $125-132$ & 1 & $11000-11999$ & 0.4 \\
\hline $191-200$ & 0.5 & ........ & & .......... & & $\ldots \ldots \ldots$ & & $\begin{array}{l}12000-12999 \\
13000-13999\end{array}$ & $\begin{array}{l}0.2 \\
0.2\end{array}$ \\
\hline
\end{tabular}

The averages show a little increase in systolic pressure and pulse rate as compared with the normals-131 as compared with 127 . There is also a somewhat greater variability in systolic, diastolic and pulse pressures and P. P. $\times$ P. R. in the patients as compared with the controls. But these differences are slight. This is of interest since it will be shown in the next paper that a marked variation from the normal can be demonstrated in this group of patients under conditions which impose a strain on the cardiovascular system.

\section{HYPERTENSION IN YOUNG MEN}

In eighteen soldiers between 21 and 31 years of age a systolic pressure of more than 150 was found on repeated daytime examinations. 
These cases are briefly reviewed here because a comparison of their basal and day measurements brought up a point which may prove to be of some importance. They can be separated into four groups in accordance with the conditions associated with the hypertension.

The first group comprises six cases in which no other evidence of disease than the hypertension was found. The following is a summary of the record of the only case in this group in which cardiac enlargement was found.

CASE 1.-Sa., aged 26; no complaint.

Mother died of heart disease. Measles and diphtheria in childhood. Pneumonia when 8 years old.

Six months ago, while doing heavy work in France, he became breathless on exertion. He reported for examination, and has been kept on light duty since then. Neither before nor since that time has he had any complaint.

The heart appeared to be enlarged and this was confirmed by roentgen-ray examination, which showed an increase in the transverse diameter. There was a systolic murmur best heard over the aortic area and audible in the neck. There was no thrill. The Wassermann was negative.

After restriction of fluids the night urine had a specific gravity of 1.025 on one occasion, and 1.030 on another. No albumin or casts were found. Phenolsulphonephthalein excretion was 80 per cent. in two hours and ten minutes after intramuscular injection.

Ophthalmoscopic examination showed a greater tortuosity than usual in the retinal vessels, but no thickening of the arteries.

Table 9.-Basal and Daytime Pressures and Pulse Rates on Hypertension Cases Not Associated with Any Discoverable Disease

\begin{tabular}{|c|c|c|c|c|c|c|c|c|c|c|}
\hline \multirow[b]{2}{*}{ Name } & \multicolumn{5}{|c|}{ Basal } & \multicolumn{5}{|c|}{ Daytime } \\
\hline & $\begin{array}{l}\text { Sys- } \\
\text { tolle }\end{array}$ & $\begin{array}{l}\text { Dias- } \\
\text { tolic }\end{array}$ & $\begin{array}{l}\text { Pulse } \\
\text { Pressure }\end{array}$ & $\begin{array}{l}\text { Pulse } \\
\text { Rate }\end{array}$ & $\begin{array}{l}\text { P. P. } \times \\
\mathbf{P} .\end{array}$ & $\begin{array}{l}\text { Sys- } \\
\text { tolie }\end{array}$ & $\begin{array}{l}\text { Dias- } \\
\text { tolic }\end{array}$ & $\begin{array}{c}\text { Pulse } \\
\text { Pressure }\end{array}$ & $\begin{array}{l}\text { Pulse } \\
\text { Rate }\end{array}$ & $\underset{\text { P. } \mathbf{P} .}{\mathbf{P}_{.}}$ \\
\hline $\begin{array}{l}\mathbf{S a} . \ldots \ldots \ldots \\
\mathbf{F} . \ldots \ldots \ldots \\
\mathbf{W} . \ldots \ldots \ldots \\
\mathbf{L} . \ldots \ldots \\
\text { Sto. } \ldots \ldots \ldots \\
\text { Stoc. } \ldots \ldots\end{array}$ & $\begin{array}{l}170 \\
140 \\
133 \\
118 \\
130 \\
120\end{array}$ & $\begin{array}{r}\mathbf{1 0 5} \\
90 \\
77 \\
73 \\
80 \\
85\end{array}$ & $\begin{array}{l}65 \\
50 \\
56 \\
45 \\
50 \\
35\end{array}$ & $\begin{array}{l}64 \\
96 \\
80 \\
80 \\
60 \\
60\end{array}$ & $\begin{array}{l}4160 \\
4800 \\
4480 \\
3600 \\
3000 \\
2100\end{array}$ & $\begin{array}{l}223 \\
155 \\
164 \\
164 \\
156 \\
168\end{array}$ & $\begin{array}{r}115 \\
80 \\
78 \\
99 \\
90 \\
95\end{array}$ & $\begin{array}{r}108 \\
75 \\
86 \\
65 \\
66 \\
73\end{array}$ & $\begin{array}{r}96 \\
122 \\
93 \\
91 \\
91 \\
86\end{array}$ & $\begin{array}{r}10380 \\
9150 \\
8000 \\
5910 \\
6006 \\
6278\end{array}$ \\
\hline
\end{tabular}

The second group includes eight patients who were all typical instances of constitutional neurocirculatory asthemia. The record of the patient $\mathrm{Ta}$ is characteristic of this group.

CASE 2.--Ta., aged 28; complains of dyspnea, palpitation, precordial pain, dizziness, frequent fainting and extreme "nervousness." Duration, twelve years or more.

His father is very nervous. His mother is subject to fits. His sister has heart trouble.

The only serious illness he remembers is typhoid fever when he was 16 years old.

He has never been able to do hard work. While he was in Italy he was three times drafted into the army, but each time he was discharged on account of disability. 
The heart showed no evidence of enlargement. There was a faint systolic murmur at the apex. The pulse rate was always regular, but usually rapid, The hands were often blue and cold and there was a marked tremor. There was no enlargement of the thyroid or protrusion of the eyes. The urine contained no albumin or casts.

Table 10.-Basal and Daytime Pressures and Pulse Rates on Hypertension Cases Associated with Neurocirculatory Asthenia (Irritable Heart).

\begin{tabular}{|c|c|c|c|c|c|c|c|c|c|c|}
\hline \multirow[b]{2}{*}{ Name } & \multicolumn{5}{|c|}{ Basal } & \multicolumn{5}{|c|}{ Daytime } \\
\hline & $\begin{array}{l}\text { Sys- } \\
\text { tolic }\end{array}$ & $\begin{array}{l}\text { Dias- } \\
\text { tolic }\end{array}$ & $\begin{array}{c}\text { Pulse } \\
\text { Pressure }\end{array}$ & $\begin{array}{l}\text { Pulse } \\
\text { Rate }\end{array}$ & $\begin{array}{c}\text { P. P. } \times \\
\text { P. R. }\end{array}$ & $\begin{array}{l}\text { Sys- } \\
\text { tolic }\end{array}$ & $\begin{array}{l}\text { Dras- } \\
\text { tolic }\end{array}$ & $\begin{array}{c}\text { Pulse } \\
\text { Pressure }\end{array}$ & $\begin{array}{l}\text { Pulse } \\
\text { Rate }\end{array}$ & $\mathrm{P}_{\mathbf{P} . \mathbf{R} .} \times$ \\
\hline $\begin{array}{l}\text { Ta........ } \\
\text { R......... } \\
\text { Seh. ....... } \\
\text { O. ....... } \\
\text { Fri. ........ } \\
\text { Greenw. ... } \\
\text { Greenb. ... }\end{array}$ & $\begin{array}{l}125 \\
135 \\
130 \\
120 \\
120 \\
113 \\
110\end{array}$ & $\begin{array}{r}70 \\
93 \\
110 \\
70 \\
90 \\
80 \\
80\end{array}$ & $\begin{array}{l}55 \\
42 \\
20 \\
50 \\
30 \\
33 \\
30\end{array}$ & $\begin{array}{l}80 \\
72 \\
84 \\
60 \\
72 \\
72 \\
72\end{array}$ & $\begin{array}{l}4400 \\
3024 \\
1680 \\
3000 \\
2160 \\
2380 \\
2160\end{array}$ & $\begin{array}{l}160 \\
158 \\
175 \\
154 \\
157 \\
177 \\
162\end{array}$ & $\begin{array}{r}91 \\
106 \\
106 \\
72 \\
88 \\
97 \\
97\end{array}$ & $\begin{array}{l}69 \\
52 \\
69 \\
82 \\
69 \\
80 \\
65\end{array}$ & $\begin{array}{r}94 \\
96 \\
124 \\
90 \\
83 \\
90 \\
97\end{array}$ & $\begin{array}{l}6490 \\
4980 \\
8550 \\
7380 \\
5720 \\
7200 \\
6305\end{array}$ \\
\hline
\end{tabular}

The third group contains two cases associated with active pyogenic infection.

CASE 3.-Ri. had experienced some shortness of breath and palpitation on exertion two years before, but these symptoms had been greatly aggravated following a mastoid and frontal sinus infection from which he was still suffering.

CASE 4.-Ch. also complained of most of the symptoms experienced by the irritable heart group, but he had a pronounced infection of the urinary tract associated with evidences of renal decompensation. His urine contained much pus and was always of low specific gravity even after restriction of fluids. His phenolsulphonephthalein excretion was 15 per cent., two hours and ten minutes after intramuscular injection. After intravenous injection, 8 per cent. was excreted in sixteen minutes from the left kidney and none from the right. Pus was seen coming from both ureters. No tubercle bacilli were found.

TABle 11.-Basal and Daytime Pressures and Pulse Rates on Hypertension Cases Associated with Pyogenic Infections

\begin{tabular}{|c|c|c|c|c|c|c|c|c|c|c|}
\hline \multirow[b]{2}{*}{ Name } & \multicolumn{5}{|c|}{ Basal } & \multicolumn{5}{|c|}{ - Daytime } \\
\hline & $\begin{array}{l}\text { Sys- } \\
\text { tolic }\end{array}$ & $\begin{array}{l}\text { Dias- } \\
\text { tolic }\end{array}$ & $\begin{array}{c}\text { Pulse } \\
\text { Pressure }\end{array}$ & $\begin{array}{l}\text { Pulse } \\
\text { Rate }\end{array}$ & $\begin{array}{l}\text { P. P. } \times \\
\text { P. R. }\end{array}$ & $\begin{array}{l}\text { Sys- } \\
\text { tolic }\end{array}$ & $\begin{array}{l}\text { Dias- } \\
\text { tolic }\end{array}$ & $\begin{array}{l}\text { Pulse } \\
\text { Pressure }\end{array}$ & $\begin{array}{l}\text { Pulse } \\
\text { Rate }\end{array}$ & $\begin{array}{l}\mathbf{P}_{\ddot{\mathbf{P}} \mathbf{.} \mathbf{R} .} \times \\
\end{array}$ \\
\hline 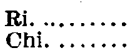 & $\begin{array}{l}135 \\
132\end{array}$ & $\begin{array}{l}90 \\
75\end{array}$ & $\begin{array}{l}45 \\
67\end{array}$ & $\begin{array}{l}68 \\
68\end{array}$ & $\begin{array}{l}3060 \\
4556\end{array}$ & $\begin{array}{l}172 \\
160\end{array}$ & $\begin{array}{r}108 \\
72\end{array}$ & $\begin{array}{l}64 \\
88\end{array}$ & $\begin{array}{l}84 \\
80\end{array}$ & $\begin{array}{l}5380 \\
7040\end{array}$ \\
\hline
\end{tabular}

In the last group there are two cases with advanced Bright's disease.

CASE 5.-R. was 21 years old. He complained of occasional headaches.

He had scarlet fever when a child. Two years ago his ankles were swollen and painful for some weeks, and a year ago there was a recurrence of this condition.

There was a diffuse retinitis in both eyes. The urine contained a moderate amount of albumin. The specific gravity never rose above 1.016 in spite of fluid restriction. The sediment showed coarsely granular and highly refractile casts, many of them three to four times broader than the usual cast. Only a trace of phenolsulphonephthalein was excreted. The blood urea concentration was $171 \mathrm{mg}$. per hundred c.c. 
CASE 6.-C. also complained of occasional headaches. His urine contained a moderate amount of albumin, and the sediment showed a fair number of blood casts. The phenolsulphonephthalein excretion was 25 per cent. in two hours and ten minutes.

Table 12.-Basal and Daytime Pressures and Pulse Rates on Hypertension Cases Associated with Advanced Bright's Disease

\begin{tabular}{|c|c|c|c|c|c|c|c|c|c|c|}
\hline \multirow[b]{2}{*}{ Name } & \multicolumn{5}{|c|}{ Basal } & \multicolumn{5}{|c|}{ Daytime } \\
\hline & $\begin{array}{l}\text { Sys- } \\
\text { tolic }\end{array}$ & $\begin{array}{l}\text { Dias- } \\
\text { tolic }\end{array}$ & $\begin{array}{c}\text { Pulse } \\
\text { Pressure }\end{array}$ & $\begin{array}{l}\text { Pulse } \\
\text { Rate }\end{array}$ & $\overline{\text { P. P. } . \times}$ & $\begin{array}{l}\text { Sys- } \\
\text { tolic }\end{array}$ & $\begin{array}{c}\text { Dias- } \\
\text { tolic }\end{array}$ & $\begin{array}{c}\text { Pulse } \\
\text { Pressure }\end{array}$ & $\begin{array}{l}\text { Pulse } \\
\text { Rate }\end{array}$ & $\begin{array}{c}\text { P.P. }_{\dot{P} . \mathbf{R} .} \\
\text { P. }\end{array}$ \\
\hline R. ........... & $\begin{array}{l}169 \\
148\end{array}$ & 118 & 51 & $\begin{array}{l}60 \\
59\end{array}$ & $\begin{array}{l}3060 \\
1652\end{array}$ & $\begin{array}{l}173 \\
167\end{array}$ & 123 & $\begin{array}{l}50 \\
60\end{array}$ & $\begin{array}{l}69 \\
66\end{array}$ & 3450 \\
\hline
\end{tabular}

Only a few of the basal measurements on these patients would have been regarded as unusual if the low average pressure and narrow range of variation of normal individuals had not been known. But taking all these figures together, the average systolic pressure in the early morning is $32 \mathrm{~mm}$. above the normal basal average as compared with a daytime systolic pressure $40 \mathrm{~mm}$. in excess of the normal daytime average. As a whole, then, these hypertension cases, selected because of their high daytime systolic pressures, still showed hypertension in the early morning when the pressor stimuli of the day were no longer in action. The point, however, which seems to me to be of special clinical significance is the wide variation in the degree of reduction of pressure during the night shown by the different individuals of this series. The first case in Group I and the two nephritic cases are distinguished from the others by the relatively slight decrease of pressure in the early morning and especially by the maintenance of high diastolic pressures. In a large series of cases it might be possible to distinguish two types of hypertension, one in which there is a pronounced fall in pressure under basal conditions and another in which the decrease is only slight. It is true that such a distinction would be one of degree only and would not necessarily depend on any difference in etiology. But from the point of view of prognosis it is surely of importance. In the patient Greenw., for instance, the average daytime pressure of 177 systolic and 97 diastolic will be more easily borne than the systolic of 167 and the diastolic of 107 in the patient $C$. with Bright's disease, because in the first case the cardiovascular system is rested each night by the fall to the basal levels of 113 and 80 , whereas in the renal case there is no remission, and the heart has continually to work against a high diastolic pressure.

\section{SUMMARY}

1. The blood pressure and pulse rate of normal persons were measured under what are called basal conditions, i. e., in the early morning before the subjects had risen from bed or taken food. These results 
are contrasted with similar measurements on normal persons under what are called daytime conditions, i. e., at any time during the day after the subjects had risen from bed and had had food, but in all cases in the recumbent position and with the exclusion of those who had recently undergone any muscular exertion, such as stair climbing or drilling. The averages obtained are shown in Table 13.

TABle 13.-Averages of Pulse Pressure and Pulse Rate

\begin{tabular}{|c|c|c|c|c|c|}
\hline $\begin{array}{l}\text { Conditions } \\
\text { Basal.................... } \\
\text { Day time.......... }\end{array}$ & $\begin{array}{c}\text { Systolic } \\
99 \\
127\end{array}$ & $\begin{array}{c}\text { Diastolic } \\
71 \\
78\end{array}$ & $\begin{array}{l}\text { Pulse Pressure } \\
28 \\
50\end{array}$ & $\begin{array}{l}\text { Pulse Rate } \\
63 \\
80\end{array}$ & P.P. $\underset{\substack{1764 \\
3980}}{\times P . R .}$ \\
\hline
\end{tabular}

2. The variability of normal basal and daytime pressures and pulse rates is defined by statistical methods and probability tables for use in clinical work are given.

3. The significance of the difference between basal and daytime pressures and pulse rates is discussed, and data on the influence of exercise and of psychic disturbance on pressure and pulse rate levels are given.

4. Measurements of basal and daytime levels were made on patients, and the deductions which may be drawn from comparison with the normal data are discussed. 